\title{
Jovens Mulheres: Motivos do Abandono Escolar na Educação de Jovens e Adultos, em Duas Unidades Escolares do Estado de Mato Grosso
}

\section{Young Women: Reasons for School Abandonment in Youth and Adult Education in Two, School Units in the State of Mato Grosso}

\author{
Enerci Candido Gomes ${ }^{\mathrm{ab}}$; Maria das Graças Campos*b

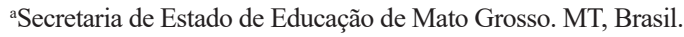

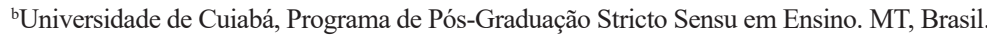 \\ *E-mail: professoramatogrosso@gmail.com.
}

\begin{abstract}
Resumo
Este trabalho apresenta recorte de uma pesquisa de mestrado, cujo objetivo foi compreender os motivos pelos quais jovens mulheres abandonam a Educação de Jovens e Adultos (EJA) na etapa Ensino Médio. Diante da complexidade e da subjetividade da temática, faz-se necessário que os procedimentos metodológicos contribuam para a aproximação sujeitos/objetos pesquisados, de modo a garantir uma maior compreensão dos problemas do abandono escolar, na perspectiva da abordagem qualitativa. Enquanto metodologia, optou-se pela utilização de fontes documentais e pela história oral. A pesquisa foi realizada em duas unidades escolares do Estado de Mato Grosso, sendo uma localizada em Várzea Grande e outra em Cuiabá. No trabalho foram entrevistadas 16 mulheres desistentes da EJA. A análise da fase documental e as primeiras entrevistas realizadas mostraram que um número expressivo de jovens mulheres, entre 18 e 25 anos de idade, que se matricularam na EJA, logo depois a abandonaram, sem concluir os estudos. Por outro lado, outras pesquisas já realizadas permitem concluir que as mulheres vêm enfrentando a exclusão escolar no sistema educacional. Nesse sentido, admite-se que os estudos realizados foram relevantes e poderão subsidiar políticas públicas educacionais para a melhoria do ensino de EJA, com o enfoque nos fatores que provocam o abandono escolar.
\end{abstract}

Palavras-chave: Abandono Escolar. Jovens Mulheres. Educação de Jovens e Adultos. Peculiaridades da Condição Feminina.

\begin{abstract}
This work presents an excerpt from a master's research, whose objective was to understand the reasons why young women abandon Youth and Adult Education (EJA) in the High School stage. In view of the complexity and subjectivity of the theme, it is necessary that the methodological procedures contribute to the approximation of subjects / objects researched, in order to guarantee a greater understanding of the problems of school dropout, from the perspective of the qualitative approach. As a methodology, it was decided to use documentary sources and oral history. The research was carried out in two school units in the State of Mato Grosso, one located in Várzea Grande and the other in Cuiabá. At work, 16 women dropping out of EJA were interviewed. The analysis of the documentary phase and the first interviews conducted showed that a significant number of young women, between 18 and 25 years of age, who enrolled in EJA, soon after abandoned it, without completing their studies. On the other hand, other research already carried out allows us to conclude that women have been facing school exclusion in the educational system. In this sense, it is admitted that the studies carried out were relevant and may subsidize public educational policies for the improvement of EJA teaching, with a focus on the factors that cause school dropout.
\end{abstract}

Keywords: Dropout. Young Women Youth and Adult Education. Peculiarities of the female condition.

\section{Introdução}

Aos altos índices de abandono escolar e a questões inerentes ao trabalho, maternidade, entre outras, que na maioria das vezes são colocados como motivos principais desse abandono. Tal problemática motivou o questionamento: além das questões aqui colocadas, quais seriam as implicações de fatores intraescolares na desistência de jovens mulheres da modalidade de ensino EJA? Para responder a esse questionamento, buscou-se evidenciar as possíveis razões por meio da análise de fontes documentais e orais em duas escolas públicas que ofertam a modalidade de ensino, sendo uma localizada em Cuiabá e outra em Várzea Grande, ambas no Estado de Mato Grosso.

Pesquisa levou em consideração os elevados índices de abandono escolar quando se trata desse público específico. Segundo dados do Instituto Brasileiro de Geografia e
Estatística (IBGE, 2010), um número expressivo de jovens entre 18 e 25 anos de idade não conclui o ensino médio, e o predomínio de mulheres entre as desistentes na EJA é o que nos dá fundamentos para a análise das principais razões, motivos que as levam a abandonarem a escola.

Outra questão fundamental foi procurar compreender a dinâmica e os motivos que levaram jovens mulheres a interromper os estudos na EJA, nos aspectos intra e extraescolares, podendo assim subsidiar a formulação de políticas educacionais para superar os altos índices de abandono escolar.

Estudos já realizados apontam que são vários os fatores que contribuem para o abandono escolar da mulher na EJA, visto que historicamente ela sempre teve dificuldade de acesso à educação formal, seja pelo fato da exclusão social relacionada às questões de gênero, seja pela sobrecarga de trabalho que envolve, dentre outros fatores, a dupla jornada 
de trabalho, já que uma grande maioria tem um emprego fora de casa para suprir as necessidades básicas da família e ainda tem de dar conta dos afazeres domésticos (SAFFIOTI, 2013).

Assim, o objetivo desse estudo é apresentar proposições de melhorias para a EJA, a fim de contribuir para a redução do abandono escolar na educação básica, em tal modalidade de ensino, a partir da investigação oportunizada pela história oral, que subsidia as narrativas das pessoas entrevistadas.

Faz-se necessário um breve parêntese e destaque à trajetória da mulher brasileira, antes da abordagem sobre a história oral, que será retomada em momento oportuno, neste texto.

Historicamente sabe-se que a luta da mulher brasileira, pela sua emancipação tem bases sólidas de desafios e enfrentamentos. E o seu acesso à educação pública tem registros no século XIX, quando da criação "da Escola Normal, em 1880, na Corte do Rio de Janeiro" dado ao sistema patriarcal que contextualiza tais barreiras. Fato este, que revela a necessidade de desvendar de forma mais sistemática, os reais motivos pelos quais ainda, mulheres em pleno século XXI interrompem seus estudos e muitas vezes os abandonam, de forma definitiva, conforme algumas narrativas da história oral desta produção.

Tais registros históricos têm sustentação sobre essas afirmações de impedimentos, no tocante à educação, pelas contribuições de pensadores como Ribeiro (2000), para quem os registros historiográficos existentes permitem afirmar que no século XVII, a Coroa portuguesa tinha como único objetivo explorar as riquezas naturais do Brasil, não havendo preocupação com o processo de colonização. Ao afirmar isso, deixa evidente que a população esteve à mercê somente da exploração de riquezas, sem atenção a outras necessidades dos cidadãos da época, como exemplo, a educação.

E nessa linha de investigação, quanto à educação de mulheres, estas ficaram excluídas do acesso à educação. Situação confirmada pelo pensador Saffioti (2013), que discute sobre o assunto

Já no final do século XVII, a mulher somente poderia receber alguma instrução nos conventos. Nessa época, moças da camada senhorial buscavam, então, instrução nos mosteiros de Portugal. [...] Mesmo assim, a instrução formal, da leitura e da escrita, era oferecida juntamente com aulas de música, canto e órgão, e dos trabalhos domésticos (SAFFIOTI, 2013, p. 270).

Em 1816, senhoras portuguesas e também francesas passaram a oferecer, ao lado dos cursos de costura e bordado, aulas de religião, rudimentos de aritmética e língua pátria, às moças que recebiam em suas casas como pensionistas (DEBRET, 1940).

Com efeito, ao longo de todo o período colonial, dialogando com Ribeiro (2000) e Saffioti (2013), sabe-se que a instrução para mulheres foi deixada de lado até que em 1823 a Constituição Federal trouxe em seus dispositivos a proposta de instrução para elas. Finalmente o sexo feminino passou a ser beneficiado.

A Constituição de 1826 garantiu o ensino primário no Império e o direito das mulheres "honestas, prudentes e dignas" à instrução, porém, associados às aulas de coser e bordar (SAFFIOTI, 2013). Segundo a autora, mulheres que se tornassem mestras (educadoras/professoras), apesar da diferença de currículos, receberiam remuneração igual ao do professor do sexo masculino. Mas, ao ser isenta de ministrar a disciplina de Geometria, sua remuneração seria mais baixa. Ou seja, as mulheres conquistaram o direito de receber salários iguais aos dos homens, porém com essa ressalva negativa de não ministrarem aulas de Geometria.

Nesse sentido, a abertura de espaço para que a mulher galgasse um posto de trabalho além das prendas domésticas caracterizou-se como mais um instrumento de discriminação entre os sexos. Assim, a ideia de que as funções da mulher como professora seria um prolongamento das funções maternas, com salários inferiores e ainda sua exclusão do ensino secundário, configurava mais uma vez a limitação às oportunidades de acesso ao conhecimento de forma igualitária pelo sexo feminino.

Na década de 1930, no governo de Getúlio Vargas, com a criação do regime denominado "Estado Novo", houve o interesse de organizar a educação de forma a atender às demandas do setor produtivo (SAUNER, 2002).

Importante enfatizar que naquela época houve necessidade de organização do Estado, em especial no setor produtivo, o que alavancou o interesse pela educação no país no intuito de formar mão de obra qualificada. Essa situação reflete consequências da Primeira Guerra Mundial e da pressão por políticas de substituição de importação. Assim, as primeiras iniciativas governamentais para lidar com o analfabetismo entre adultos tiveram início na década de 1940, com o objetivo de acelerar o crescimento econômico do país (BRASIL, 2006).

Mais tarde, na década de 1950, devido ao notório desenvolvimento do país e ao grande número de adultos analfabetos, os quais não tinham o direito ao voto, as políticas de EJA ganharam ênfase (MOURA, 2006). Nesse sentido, observa-se que a alfabetização de adultos teve o propósito inicial de transformar o analfabeto em um eleitor potencial.

No início da década de 1950, quase $60 \%$ dos cidadãos maiores de dezoito anos era formada por analfabetos, o que levou o governo a criar programas de alfabetização para essa parcela de jovens adultos. Em 1952 criou-se a Campanha Nacional de Educação Rural, a CNER, para atender o Estado do Nordeste.

Com tal incentivo, vários programas e movimentos foram criados, como o Movimento de Educação de Base - MEB, sob liderança da Conferência Nacional de Bispos do Brasil CNBB (ALMEIDA; CORSO, 2015).

Na década de 1960, registra-se a contribuição de Paulo Freire e dos movimentos sociais para construir uma intensa e 
organizada alfabetização de adultos sem distinção de gênero. As campanhas de educação de adultos findaram-se no ano de 1963. E em seguida, o governo colocou nas mãos de Paulo Freire, a responsabilidade de criar um Programa Nacional de Alfabetização. Contudo, na vigência do golpe militar, todos esses planos foram frustrados com o exílio de Paulo Freire, e o governo militar lança o Mobral - Movimento Brasileiro de Alfabetização

Para o Conselho Nacional de Educação - CNE, a EJAé uma modalidade do ensino fundamental e médio que possibilita recuperar anos de estudo a muitas pessoas que não tiveram acesso à educação formal em idade regular (BRASIL, 2008). Portanto, surge a oportunidade para jovens e adultos iniciar e /ou dar continuidade aos seus estudos, sendo, portanto, uma modalidade de ensino que visa garantir o direito daqueles que foram excluídos dos bancos escolares ou que não tiveram oportunidade de acessá-los.

Ainda que reconhecida pela Constituição como um direito garantido a toda pessoa humana, o estudo na EJA sempre enfrentou muitos desafios, uma vez que não basta apenas um grande número de matrículas, mas que esses jovens e adultos pudessem e tivessem condições de prosseguir com seus estudos, sem interrupção antes de finalizar o ensino médio, fim da etapa da educação básica.

Segundo Freire (2008), a educação tem caráter permanente e contínuo, e o homem, um ser incompleto, inacabado por natureza, deve estar sempre em formação. Partindo desse pressuposto, é possível afirmar que não haveria educação se o homem fosse um ser acabado. Em outras palavras, a aprendizagem contínua é inerente ao ser humano, portanto, "nunca é tarde para aprender", pois, ratificando que, a Constituição Federal conduz essa afirmação, ao concordar, no art. 205, de que "toda e qualquer educação visa o pleno desenvolvimento da pessoa, seu preparo para o exercício da cidadania e sua qualificação para o trabalho".

Esse parâmetro foi reafirmado na Lei de Diretrizes e Bases da Educação Nacional - LDB nº 9.394/96, art. 2º, quando fala do conjunto das pessoas e dos educandos como "um universo de referência sem limitações". A partir de então, a EJA tornou-se uma modalidade de ensino estratégica, que representa o esforço da Nação em prol da igualdade de acesso à educação como bem social. Esse direito constitucionalizado é cercado de mecanismos financeiros e jurídicos, quais sejam: LDB 9.394.96; Parecer CNE/CEB No11/2000; Resolução CNE/CEB No01/2000; Plano Nacional de Educação (Lei 10.172/01); Plano de Desenvolvimento da Educação e em compromissos e acordos internacionais.

Ressalta-se que a LDB 9.394/96 trata da EJA no Título V, capítulo II, como modalidade da educação básica, superando sua dimensão de ensino supletivo, regulamentando sua oferta a todos aqueles que não tiveram acesso ou não concluíram o ensino fundamental.

Do mesmo modo, o parágrafo $2^{\circ}$ da mesma lei atribui ao Poder Público viabilizar e estimular o acesso e permanência do trabalhador na escola, mediante ações integradas e complementares entre si. Enfatizando que de acordo com a LDB 9.394/96 os alunos do EJA deverão ser atendidos no âmbito da Educação Básica, por meio da Diretoria de Políticas de Educação de Jovens e Adultos, da Secretaria de Educação Continuada, Alfabetização e Diversidade (Secad/ MEC), que tem priorizado um processo amplo, democrático e participativo na construção de uma política pública de Estado para a EJA. Essas ações têm fortalecido e estreitado a parceria entre estados e governo federal, na busca pela ampliação e melhoria da qualidade da EJA. Entretanto, verifica-se que um elevado número de jovens e adultos, mesmo tendo a oportunidade de retomar os estudos, não consegue concluir a educação básica.

Essa discrepância entre o número dos alunos matriculados e a defasagem na continuidade e conclusão dos estudos foi constatada na pesquisa, no decorrer da fase documental, quando os arquivos escolares foram analisados. Nessa direção, as autoras Kripka, Schelle, Bonotto (2015) enfatizam as possibilidades da pesquisa documental, quando utilizada para análise de um projeto ou processo escolar, sendo que a escrituração, os relatórios podem ter muita utilidade.

Para apreensão dos dados e melhor compreensão sobre a realidade das entrevistadas, optou-se pela utilização da ferramenta história oral que, na concepção de alguns autores, nesse tipo de estudo, pode ser de grande relevância.

As fontes orais ampliam as possibilidades de informações, para além de um indivíduo acolhido, aceitos ou não em meios sociais. E também oportunizam "incorporar não apenas indivíduos à construção do discurso do historiador", além de possibilitar entender contextos e acontecimentos antes desconhecidos (GARRIDO, 1993).

Retomando as discussões sobre os recursos da história oral na condução das investigações acerca da trajetória das entrevistadas neste documento, pode-se contar com as contribuições de Thompson (1998), que faz a seguinte afirmação sobre essa linha de trabalho da história oral.

Ampliando as discussões com bases na história oral, percebe-se que, diante da necessidade de compreensão das manifestações das participantes da pesquisa, no processo de análise dos dados, tomou-se como referência Bardin (1995), que afirma:

Tais informações agregadas às que se seguem, delineiam o passo a passo para a execução desta pesquisa, sempre amparada pelas bases teóricas afins.

\section{Material e Métodos}

Optou-se pela utilização de pesquisa bibliográfica, fontes documentais e pela história oral, que irá contribuir sobre as possibilidades de participação das jovens mulheres no processo histórico, visando conhecer e aprofundar aspectos sobre determinada realidade, como os padrões culturais, as estruturas sociais, os processos históricos ou os laços do cotidiano (CHIZZOTTI, 1991). 
Alberti (2004) afirma que na metodologia da história oral tem-se a oportunidade de se estar diante do fascínio do vivido, enfatizando também a experiência histórica do entrevistado, tornando o passado mais concreto.

Os relatos das pessoas em pesquisa nos permitiram compreender a singularidade na convivência social. Dessa maneira, foi possível encontrar a versão da história que não foi narrada pelos meios oficiais. Daí a possibilidade fascinante de descobertas, pois a história oral:

[...] nos dá a chance, ou ilusão, de surpreendermos, um pouco que seja, a impossibilidade de assistir a um filme do passado. Quando isso acontece, é porque nela encontramos a vivacidade do passado, a possibilidade de revivê-lo pela experiência do entrevistado. Não é à toa que a isso muitos dão o nome de história (ou memória) viva. (ALBERTI, 2004, p. 14).

A importância de se analisar processos pessoais e informais, não previstos em documentos oficiais é também enfatizada por Müller (2007), ao justificar as estratégias metodológicas adotadas em seu trabalho de pesquisa com professoras primárias um documento oficial, de Estado, nem sempre reflete o processo histórico da forma como ocorreu ou reflete apenas a intenção daqueles grupos que em um determinado momento histórico estavam no poder.

A pesquisa, nas duas unidades citadas contou com um total de 16 entrevistadas. Inicialmente foram selecionadas as publicações, priorizando autores contemporâneos que versam sobre o tema abordado, para o embasamento teórico do estudo; posteriormente foram analisados documentos das jovens mulheres matriculadas na EJA entre 2012 e 2016, que desistiram de estudar na etapa do ensino médio, constantes dos arquivos das duas escolas pesquisadas.

E ao final, de forma aleatória fez-se a seleção dos documentos das 16 jovens mulheres das escolas que compõem o universo da pesquisa e que desistiram da EJA. Foram então escolhidas como participantes entrevistadas, objetivando identificar variáveis qualitativas, bem como as possíveis causas do abandono escolar, antes de concluírem o ensino médio, etapa escolhida na pesquisa.

Dessa maneira, além da técnica de história oral, foram estudados os documentos que fazem parte dos arquivos das escolas, tais como atas e fichas individuais das alunas escolhidas para a análise. O diálogo foi mais intenso com os autores que discorrem sobre as temáticas de questões de gênero e abandono escolar, com ênfase na EJA. Nesse sentido, foram estudadas as obras e as produções científicas dos autores: Bardin (1995), Bourdieu (1999), Thompson (1998), Ferreira (2007), Saffioti (2013), Freire (2000), para melhor contextualização dos temas que foram abordados na pesquisa.

\section{Resultados e Discussão}

Os dados obtidos com a pesquisa documental apontaram que entre os anos de 2012 e 2016, nas duas unidades escolares do Estado de Mato Grosso, foram matriculados na EJA etapa ensino médio 8.002 alunos, destes, 2.795 abandonaram os estudos, sendo 1.486 eram mulheres.

Além das informações levantadas no acervo documental das escolas pesquisadas, foram envidados diálogos com os gestores escolares e com as ex-alunas entrevistadas, realizando, ainda, consultas na plataforma virtual de aprendizagem do Sistema Integrado de Gestão Educacional (SIGEDUCA). Para obtenção dos demais dados acerca do tema, foram analisados alguns documentos disponibilizados pelas secretarias das escolas, tais como: atas de resultados finais, fichas individuais dos alunos, por situação a partir da matrícula até o abandono, compreendendo o período de 2012 a 2016.

A pesquisa documental e a coleta de dados possibilitaram colocar em evidência informações referentes a data e ano de nascimento das jovens mulheres, telefone e endereço para posterior contato e realização das entrevistas, como parte fundamental do estudo, de maneira a dar voz a quem não se encontra mais inserida nas unidades escolares pesquisadas.

As entrevistas foram realizadas com posterior transcrição e apresentação dos dados, em forma de gráficos, de modo a possibilitar maior compressão do leitor. Contudo, na etapa inicial, houve uma grande dificuldade em localizar as jovens mulheres que desistiram da EJA, selecionadas para compor o universo empírico da pesquisa, uma vez que os dados constantes nos arquivos das duas escolas se encontravam desatualizados, o que tem dificultado o contato da escola com elas para lhes oferecer uma nova oportunidade de retomar os estudos, haja vista que muitas se quer têm endereço fixo, por morar de aluguel e mudar constantemente de localização, e mesmo o telefone de contato deixado em seus cadastros não existe mais, pois costumam trocá-lo com muita facilidade.

Outra dificuldade encontrada foi a localização de uma das escolas, o que vem refletindo na mobilidade e acesso das mulheres, sendo observado que quando a escola é localizada no próprio bairro os índices de desistência são menores se comparados à desistência nas escolas localizadas no centro da cidade, conforme informações obtidas nas entrevistas. Obviamente, o fato de morar próximo às unidades escolares analisadas pode contribuir para a frequência às aulas, uma vez que não é necessário se deslocar para tão longe de suas moradias para estar na sala de aula. Conforme a fala da Jasmim, uma das ex-alunas entrevistadas:

Eu trabalhava e dependia de ônibus, saía às 6 horas, chegava já era 7h20, 7 e meia. O cansaço do serviço. Escola mais perto encerrou o curso e a próxima era muito longe. Chegada dos filhos. (Entrevistada Jasmim, 2018)

Nesse contexto, é importante salientar que a EJA é uma proposta que exige uma reflexão diferente das outras modalidades de ensino regular, que possa atender a todos que não tiveram oportunidade de acesso à educação em seu tempo e idade; essas jovens mulheres apresentam uma vulnerabilidade social quase sempre vista nesta modalidade de ensino. Para Arroyo (2005, p. 29), esses jovens e adultos são integrantes de uma mesma sociedade com direitos a frequentar a escola que é 
para todos, pois trazem em suas histórias de vidas experiências que são singulares.

Figura 1 - Alunos matriculados na EJA - Escola A Total de Alunos Matriculados (1.307)

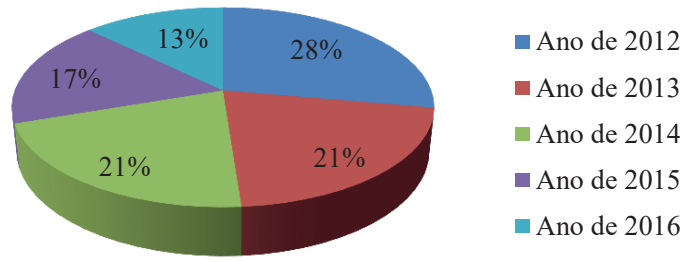

Fonte: Dados da pesquisa.

Os dados representados no gráfico da Figura 1 mostram que entre os anos de 2012 e 2016 um número significativo de alunos foi matriculado na Escola "A", localizada em CuiabáMT, sendo: 363 em 2012, 275 em 2013, 274 em 2014, 228 em 2015, e 167 em 2016, perfazendo o total de 1.307 alunos somente no curso de EJA de 2012 a 2016. O maior número de alunos matriculados (363) foi no ano de 2012; já o menor (167) em 2016, o que se deve ao fato de esse ter sido o último ano em que a esta escola ofertou a EJA.

Figura 2- Alunos matriculados na EJA - Escola "B" Total de Alunos Matriculados (6.695)

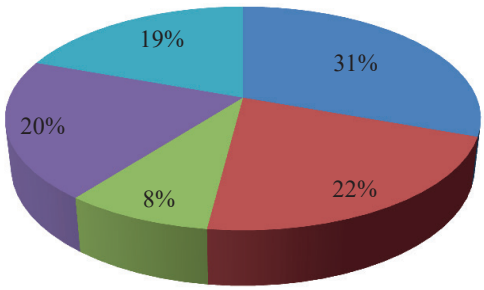

- Ano de 2012

- Ano de 2013

Ano de 2014

- Ano de 2015

Ano de 2016

Fonte: Dados da pesquisa.

Os dados representados no gráfico da Figura 2 mostram que entre os anos de 2012 e 2016 foram matriculados na Escola B, localizada no município de Várzea Grande, 6.695 alunos. Matrículas realizadas por ano: 1.439 em 2012; 1.345 em 2013; 566 em 2014; 1.302 em 2015 e 2.043 em 2016. O ano com maior número de matrículas na EJA nessa escola foi 2012 e o com menor número foi 2014.

Quanto aos alunos matriculados e os desistentes no período de 2012 a 2016, nas duas escolas analisadas, há o seguinte resultado: dos 1.307 alunos matriculados na EJA, entre os anos de 2012 a 2016, na Escola A, apenas 685 (ou $52 \%$ ) concluíram o curso, já 622 (ou 48\%) desistiram antes de concluir o curso da EJA.

Quanto aos alunos da Escola B, que concluíram e os que desistiram dos estudos da EJA, os dados apresentados relativos aos matriculados entre 2012 e 2016 dessa Escola B, mostram os seguintes resultados: que 4.522 alunos (ou 68\%) do total conseguiram concluir a EJA, enquanto que 2.173 (ou $32 \%$ ) desistiram antes da conclusão do curso.

Tais dados sobre a EJA na Escola B corroboram com os dados do Censo Escolar 2010, do Instituto Brasileiro de Geografia e Estatística (IBGE), que mostram que um número expressivo de jovens entre 18 e 25 anos de idade não conclui o ensino médio, e mesmo quando retornam à escola nos cursos de EJA desistem antes do término do ano letivo.

Essa constatação reafirma a hipótese levantada e confirmada por Digiácomo (2005) de que a evasão escolar é um problema crônico em todo o Brasil, sendo muitas vezes passivamente assimilada e tolerada por escolas e sistemas de ensino. Para esse mesmo autor, muitas escolas chegam a ponto de admitir a matrícula de um número mais elevado de alunos (o que equivale a constituir turmas bem maiores que o adequado), já contando com a desistência de muitos ao longo do período letivo.

Meksenas (1992) informa que na EJA a evasão escolar acontece devido a diversos fatores: necessidade de trabalhar fora, exaustiva jornada de trabalho, baixa qualidade do ensino. Assim, muitos desistem dos estudos sem completar essa etapa da educação básica, conforme se depreende da fala de uma das entrevistadas.

Cansaço; trabalhava dia inteiro, $[. .$.$] chegava em casa, ainda$ tinha que cuidar da casa, das crianças [...] ia pra escola e ficava cochilando, não estava conseguindo aprender quase nada. Aí abandonei a escola. (Entrevistada Petúnia, 2018).

Outros dados interessantes que reforçam o já constatado por outras pesquisas, a exemplo das publicadas pelo Ministério da Educação com base nos censos escolares, mostram que do total de alunos desistentes na EJA a maioria é do sexo feminino, dados esses confirmados na análise documental das duas escolas pesquisadas, sobre alunas mulheres que abandonaram a EJA nas Escolas A e B.

Os dados mostram que, na EJA da Escola A, entre alunos que abandonaram os estudos, 53\% eram mulheres, contra $47 \%$ dos homens. E na Escola B, do total de 2.172 alunos desistentes entre 2012 e 2016. Nada menos que 1.157 (ou $53 \%$ ) também eram do sexo feminino. Portanto, o fato do total de alunos desistentes, a maioria ser composta por mulheres, corrobora com a afirmação de Saffioti (2013) de que a evasão escolar se deve ao fato de a mulher sempre ter tido dificuldades de acesso e permanência escolar.

Essa observação pode ser o caso das duas escolas pesquisadas, haja vista verificar-se um número significativo de alunos no início do ano letivo e um percentual considerável de desistência, predominantemente entre as mulheres.

Por fim, enfatiza-se que o percentual de $53 \%$ de mulheres que desistiram da EJA, identificado na análise documental das duas escolas, aponta um elevado índice de desistência delas, considerando que mais da metade dos desistentes são do sexo feminino.

Esta pesquisa apresenta a seguir as informações coletadas conforme análises de conteúdo propostas por Bardin (1995), e estão apresentadas em categorias, de acordo com os questionamentos suscitados e as respostas obtidas, para melhor 
visualização e leitura. Posteriormente, foram realizadas as análises das falas das entrevistadas com simultânea discussão.

Quadro 1- Principais dificuldades em sala de aula

\begin{tabular}{|l|l|l|}
\hline 1 & $\begin{array}{l}\text { Nenhuma } \\
\text { dificuldade }\end{array}$ & $\begin{array}{l}\text { Das entrevistadas, 31\% responderam que } \\
\text { não encontraram nenhuma dificuldade em } \\
\text { sala de aula. }\end{array}$ \\
\hline 2 & $\begin{array}{l}\text { Acompanhar } \\
\text { os conteúdos }\end{array}$ & $\begin{array}{l}\text { Já } 25 \% \text { delas afirmaram ser a principal } \\
\text { dificuldade encontrada em sala de aula } \\
\text { acompanhar os conteúdos, em especial } \\
\text { nas aulas de Matemática. }\end{array}$ \\
\hline 3 & $\begin{array}{l}\text { Falta de } \\
\text { domínio dos } \\
\text { professores } \\
\text { para coibir a } \\
\text { bagunça }\end{array}$ & $\begin{array}{l}\text { Das entrevistadas, 25\% também citaram } \\
\text { a falta de domínio dos professores em } \\
\text { coibir a bagunça dos colegas como sendo } \\
\text { uma dificuldade. }\end{array}$ \\
\hline 4 & $\begin{array}{l}\text { Tempo em sala } \\
\text { de aula após o } \\
\text { trabalho }\end{array}$ & $\begin{array}{l}\text { Nessa questão, 13\% relataram o tempo, } \\
\text { após o trabalho, como uma das principais } \\
\text { dificuldades em permanecer na sala } \\
\text { de aula, e apenas uma relatou que não } \\
\text { saberia avaliar, pois não estava indo à } \\
\text { escola após o nascimento do filho. }\end{array}$ \\
\hline
\end{tabular}

Observa se também que a falta de suporte e apoio familiar para as alunas frequentarem a escola vem ocasionando o abandono escolar e tal fato remete à necessidade de instituir políticas públicas de atendimento às necessidades inerentes ao processo educativo dessas jovens, conforme o que demonstra o Quadro 2:

Quadro 2 - Principais motivos da desistência escolar na EJA

\begin{tabular}{|c|l|l|}
\hline 1 & $\begin{array}{l}\text { Não tinha com } \\
\text { quem deixar os } \\
\text { filhos pequenos }\end{array}$ & $\begin{array}{l}\text { Das entrevistadas, 32\% apontaram como } \\
\text { principal motivo para a desistência da } \\
\text { EJA não ter com quem deixar os filhos } \\
\text { pequenos. }\end{array}$ \\
\hline 2 & $\begin{array}{l}\text { Problema de } \\
\text { saúde }\end{array}$ & $\begin{array}{l}\text { 6\% disseram que por problemas de saúde } \\
\text { não puderam continuar os estudos }\end{array}$ \\
\hline $\begin{array}{l}\text { Dificuldade } \\
\text { em conciliar } \\
\text { trabalho, } \\
\text { afazeres } \\
\text { domésticos e } \\
\text { estudar. }\end{array}$ & $\begin{array}{l}31 \% \text { disseram ter desistido porque não } \\
\text { conseguiram conciliar o trabalho com os } \\
\text { afazeres domésticos e os estudos }\end{array}$ \\
\hline 4 & $\begin{array}{l}\text { Falta de apoio } \\
\text { e incentivo da } \\
\text { família }\end{array}$ & $\begin{array}{l}25 \% \text { disseram que faltou apoio e } \\
\text { incentivo da família, inclusive em cuidar } \\
\text { dos filhos enquanto elas estudavam. }\end{array}$ \\
\hline 5 & $\begin{array}{l}\text { Dificuldades } \\
\text { com os } \\
\text { professores }\end{array}$ & $\begin{array}{l}6 \% \text { apontaram que tiveram problemas } \\
\text { com os professores }\end{array}$ \\
\hline
\end{tabular}

Fonte: Dados da pesquisa.

Uma questão relevante se relaciona à fragilidade da estrutura de saúde pública no caso dessas estudantes tiveram seu processo educativo interrompido. Dessa forma, verificouse que, quando trata se de mulheres, as dificuldades são inúmeras, se consideradas as várias atividades que exercem. Observa-se ainda a ausência de programas públicos privados de apoio e incentivo para que as alunas possam conciliar as atividades educativas com atuação no mercado de trabalho, em especial, após a maternidade e cuidado com os filhos.

O tema "jovens mulheres na EJA: motivos do abandono escolar" suscitou muito interesse, uma vez que em virtude do trabalho, na rede pública escolar tem se observado os altos índices de abandono dos alunos da EJA e, ao longo dos estudos e da pesquisa de mestrado, constatou-se uma quantidade significativa de alunas entre 18 e 25 anos matriculadas, mas que não haviam conseguido concluir o curso, em razão de motivos intra e extraescolares.

Dessa forma, pode-se afirmar que são vários os fatores que contribuem para o abandono escolar, dentre esses a maternidade e suas consequências, apontada por diversos autores como uma de suas principais causas, contudo, fatores culturais, econômicos e sociais também podem somar para essa desistência.

As análises advindas da pesquisa apontam para a necessidade de adaptar os programas, currículos, horários e estrutura das instituições de ensino, de modo que os alunos trabalhadores tenham sucesso na escola e, consequentemente, superem as dificuldades da permanência e conclusão dos estudos.

No contexto da evasão escolar, entendemos que a aplicação das leis educacionais e normas internas das unidades escolares pesquisadas precisam estar em consonância com a realidade dos alunos da EJA.

Outra questão relevante é a formação dos professores e dos demais profissionais da escola. Tal iniciativa deve contemplar as peculiaridades deste segmento educativo, principalmente no que se refere à inclusão de propostas específicas para a modalidade de ensino no Projeto Político Pedagógico.

\section{Conclusão}

Conclui-se que a mediação, o apoio familiar, bem como do poder público por meio de políticas públicas educacionais direcionadas às mulheres e à EJA são imprescindíveis, principalmente no momento em que a jovem mulher decide pela continuidade dos estudos, visto que a escola ainda é uma das fontes de conhecimento que possibilita ao ser humano ter uma educação formal e, consequentemente, um melhor desempenho na vida e no trabalho.

Espera-se que os resultados obtidos neste estudo possam apresentar proposições de melhorias para a EJA, a fim de contribuir para a redução da evasão escolar da educação básica, na modalidade de ensino em questão, afinal ela é de fundamental importância para jovens mulheres que, por diversos motivos, não conseguiram fazer esse percurso e finalizar a educação básica.

Pelo fato de ainda nos dias atuais se tratar de uma modalidade diferenciada de atendimento da educação básica, o tema poderá ser aprofundado em pesquisas futuras. Nesse sentido, este trabalho poderá contribuir com elementos de reflexão para as escolas participantes da pesquisa, bem como para estudantes e profissionais da EJA, que possam apontar caminhos e compreender as especificidades dessa modalidade educativa, entendendo-se que as jovens mulheres não só têm o direito de ingressarem na escola como também de permanecer e concluir o ensino, com uma aprendizagem satisfatória. 


\section{Referências}

ALBERTI, V. Ouvir contar: textos em história oral. Rio de Janeiro: FGV, 2014.

ALMEIDA, A.; CORSO, A.M. A Educação de Jovens e Adultos: aspectos históricos e sociais. Curitiba. PUCPR, 2015.

ARROYO, M.G. Educação de jovens-adultos: um campo de direitos e de responsabilidade pública. In: SOARES, L.; GIOVANETTI, M.A.G.C.; GOMES, N.L. Diálogos na educação de jovens e adultos. Belo Horizonte: Autêntica, 2005. p 19-50.

BARDIN, L. Análise de conteúdo. Lisboa: Edições 70, 1995.

BOURDIEU, P. A dominação masculina. Rio de Janeiro: Bertrand Brasil, 1999.

BRASIL. Constituição da República Federativa do Brasil. Brasília, DF: Senado Federal, 1988.

BRASIL. PARECER CNE/CEB. Institui Diretrizes Operacionais para a Educação de Jovens e Adultos (EJA) nos aspectos relativos à duração dos cursos e idade mínima para ingresso nos cursos de EJA; idade mínima e certificação nos exames de EJA; e Educação de Jovens e Adultos, desenvolvida por meio da Educação a Distância. Brasília: MEC, 2008.

BRASIL. LDB. Lei 9394/96 - Lei de Diretrizes e Bases da Educação Nacional. Brasília: MEC, 1996.

BRASIL. IBGE. Censo Demográfico 2010. Disponível em: $<$ http://www.censo2010.ibge.

gov.br>. Acesso em: 11 jun. 2018.

BRASIL. Instituto Nacional de Estudos e Pesquisas Educacionais. Censo Escolar da Educação de Jovens e Adultos, Brasília: Ministério da Educação e Cultura. 2006.

CHIZZOTTI, A. Pesquisa em ciências humanas e sociais. São Paulo: Cortez, 1991.

DEBRET, J.B. Viagem pitoresca e histórica ao Brasil. São Paulo: Livraria Martins, 1940.
DIGIÁCOMO, M. J. Evasão escolar: não basta só comunicar e depois lavar as mãos. 2005. Disponível em: <www.mp.mg.gov. br>. Acesso em: 15 nov. 2019.

FERREIRA, A.T. Ler e escrever são também uma questão de gênero. In: LEAL, T. Desafios da educação de jovens e adultos: construindo práticas de alfabetização. Belo Horizonte: Autêntica, 2007.

FREIRE, P. Pedagogia da esperança, um reencontro com a pedagogia do oprimido. Rio de Janeiro: Paz e Terra, 2008.

FREIRE, P. Pedagogia da autonomia: saberes necessários à prática educativa. São Paulo: Paz e Terra, 2000.

GARRIDO, LA. As fontes orais na pesquisa histórica: uma contribuição ao debate. Rev Bras. Hist., v.13, n.25/26, p.33, 1993

KRIPKA, R.M.L; SCHELLER, M, BONOTTO, D. L. Pesquisa documental na pesquisa qualitativa: conceitos e caracterização. Rev. Investigaciones, v. 14, n.2, 2015.

MEKSENAS, P. Sociologia da Educação: uma introdução ao estudo da escola no processo de transformação social. São Paulo: Cortez, 1992.

MOURA. T.M.M. A prática pedagógica dos alfabetizadores de jovens e adultos: contribuições de Freire, Ferrero e Vygotsky. Maceió: Edufal, 2006.

MÜLLER, L. As construtoras da nação: professoras primárias na Primeira República. Niterói: Intertexto, 2007.

RIBEIRO, M.L.S. História da educação brasileira: a organização escolar. Campinas: Autores Associados, 2000.

SAFFIOTI, H. A mulher na sociedade de classes. Mito e realidade. São Paulo: Expressão Popular, 2013.

SAUNER, N.F.M. Alfabetização de adultos. Curitiba: Juruá, 2002.

THOMPSON, P. A voz do passado: história oral. São Paulo: Paz e Terra, 1998. 